\title{
The Global Photonics Education Network: another way to think globally and act locally
}

Chandrasekhar Roychoudhuri, Marc Nantel

Chandrasekhar Roychoudhuri, Marc Nantel, "The Global Photonics Education Network: another way to think globally and act locally," Proc. SPIE 9663, Eighth International Topical Meeting on Education and Training in Optics and Photonics, 96630H (6 October 2003); doi: 10.1117/12.2207349

SPIE Event: Eighth International Topical Meeting on Education and Training in Optics and Photonics, 2003, Tucson, Arizona, United States 


\title{
The Global Photonics Education Network: Another Way to Think Globally and Act Locally
}

\author{
Chandrasekhar Roychoudhuri \\ Photonics Lab., Physics Department, University of Connecticut, Storrs, CT 06269 \\ (860) 486-2587, (860) 486-1033(fax); Chandra@phys.uconn.edu \\ Marc Nantel \\ Photonics Research Ontario, Suite 331, 60 St-George Street, Toronto, ON, Canada M5S 1 A7 \\ (416) 978-3932, (416) 978-3936 (fax), mnantel@pro.on.ca
}

\begin{abstract}
As the world gets smaller through globalization and telecommunication, it also gets richer in possibilities. Empowering the educators to exchange ideas on successes and mistakes continually on the global stage while working to improve the education on their local stages can galvanize those potential richness. Our goal is to enhance this global inter-connectedness by facilitating the local intra-connectedness among the regional educators and their organizations, which can form local education clusters.

(C)2003 Optical Society of America

OCIS codes: (000.2060) Education, (000.1200) Announcements, awards, news, and organizational activities
\end{abstract}

\section{Introduction}

We live in a time when there are such astounding telecommunications tools (from telephones to the World Wide Web) that there should never be any more need to re-invent the wheel. If these tools can be used to their fullest, once new knowledge is generated it can be disseminated for all to implement in ways best adapted to their particular location, situation and need. It is imperative to apply this principle to education throughout the world. Without higher education, one cannot participate fully in today's knowledge economy. Higher education is often too expensive: only $1 / 3$ of the population can afford it, even in most developed countries. Physical infrastructure does not exist to accommodate the other $2 / 3$ of the population. Even if the infrastructure were to be created, the cost would skyrocket. Without a much larger base of educated people, the global knowledge economy cannot grow in a sustainable way.

A key sector that in many ways epitomizes the knowledge economy is the photonics industry. Let us develop a system for knowledge creation, organization and delivery of optics/photonics education and training that is economically accessible and functionally evolutionary. Just as the brain is made of interconnected individual neurons that become greater together than the sum of their parts, we can establish a global network that interconnects photonics educators in a way that enhances their work at a local scale through interacting with their peers globally. The end-result should be a net increase in the quality and quantity of good photonics education material and delivery worldwide, with a decrease in overall cost. This will make photonics education and training available to more people - including some who could not otherwise afford it - in more interesting ways.

The model on which this Global Photonics Education Network can be built, at least when it comes to its infrastructure, is that of clusters. "Clusters" are local organizations regrouping people with common goals with a desire to band together to forward these goals, still allowing them to compete in the global market. It is a wellknown model in the business world, well analyzed by Michael Porter of Harvard Business School and applied to the photonics industry sector by Robert Breault of Breault Research Organization. Each local cluster often establishes links with other like-minded clusters from other parts of the world and "clusters of clusters" can be formed, enhancing the effect of the local clusters (getting better deals from suppliers, affecting political decisions, influencing financial laws...). Such a model can be developed - and is in fact currently being developed - for photonics education and training. Examples of local photonics education clusters include the Ontario Photonics Education and Training Association (OPETA) in Ontario, Canada, the National Alliance for Photonics Education and Training (NAPET) in Singapore). We should encourage the formation of other local clusters around the world and provide the overarching "cluster of clusters" through the Global Photonics Education Network (GPEN). The modern cluster concept is an excellent example of "think globally, act locally", advised by Buckminster Fuller. It is philosophically inspiring and, yet, a pragmatic methodology for building stable and sustainable global economy. 


\subsection{Why Optics/Photonics?}

Since ancient times, a large number of the conceptual breakthroughs in science and technology, promoting our material (economic) well-being, are being facilitated by optics (and photonics). Early astronomy and the discovery of telescopes led us to appreciate the significance of adopting the Helio-centric philosophy and reject the Earth-centric, anthropo-centric path, and opened our minds to explore the vast, cosmic universe. The discovery of early microscopy opened up the floodgates to explore the microscopic wonders behind the diverse, terrestrial bound, living universe. During the last couple of centuries, studies on spectrometry, characteristic atomic spectra, the nature of light and the measurement of spectral Doppler shifts, have given us the models and tools of revolutionary nature to expand our understanding of both the microscopic and the macroscopic universes. Even today, the most precise and delicate measuring tools for the galactic, atomic and nano-particles, are optical or photonic, because photons are mass-less entities of most precise frequencies. Today's "Global Village" and "Global Economy" are the direct results of fiber optics communication and the internet revolution, all enabled by the photonics industry. The discoveries and inventions during the first part of the twenty-first century will certainly be dominated by the broad enabling power of optics/photonics science and technology. Thus, developing infrastructure for the rapid spread of optics education is of global importance.

\subsection{Economic consequences of advancement in science and technology}

Knowledge has become the "capital" for today's science and technology driven global economy. The rate of innovation has become the key metric for global competitiveness. Properly educated knowledge workers can learn to create wealth for themselves even in the poorest countries. Development (i.e., wealth creation) has become synonymous with quality education, and consequent freedom of mind. In the process, the socio-political interrelations and the governing processes have been undergoing radical changes. The meaning of "management" is changing from "controlling hired hands" to "empowering and inspiring knowledge workers to innovate". Even paradigms like "demand and supply" and economic theory based on "limited natural resources" are beginning to change to "abundance through technology" ushering in "empowered economy" of "supply for all real needs", because we now have the knowledge and technology to transform almost any material to any other desired materials. It is only a matter of cost of the energy necessary for this transmutation and transformation. Sustainable knowledge economy now needs universal education, like universal suffrage. Let us do our part to globalize optics/photonics education.

\subsection{Knowledge economy demanding faster socio-political changes}

Before the invention of paper and then printing machines, preservation of the accuracy ("purity") of human knowledge was a difficult and delicate endeavour. Privileged class had to evolve to preserve and teach to new generations. Consequently, we evolved into an educational system that is essentially "of the elite, by the elite, and for the elite", out of necessity. Now we have the other extreme: the internet is over-flooded with information or "content". But, the problem is how to create usable knowledge out of this overflowing information and then how to use the knowledge to create wealth for the well-being of all in society. While the poor of the world are far better off today than any time in the past, the empowering knowledge gap and wealth gap are rising much faster than any time in history.

Without higher education, one cannot participate in today's knowledge economy. In spite of the overflow of free information, higher education is too expensive. Barely $1 / 3$ of the population can afford it even in the most developed countries. Physical infrastructure does not exist to accommodate the other $2 / 3$ of the population. Even if the infrastructure is created, the cost of its use will skyrocket, barring all but a few wealthy elites. Yet, without a much larger number of innovators (through higher education), a country's industry cannot compete in the global knowledge economy. We must promote the evolution of new, high-quality educational models that can reach out to global billions within their economic reach. Instead of just handing out fish, we need to figure out how to help people learn for themselves "how to catch fish" while, at the same time, nurture the fish habitat for sustainability.

\subsection{Mass education needs novel approaches to reach out to a diversity of students}

All people are born with some 100 billion neural cells. To sustain the evolution of the specie, different social members are genetically endowed with different modes of creative intelligence and learning skills. However, the current academic evaluation system favors left-brain, analytical and articulate group. This may represent about 15$20 \%$ of the population. The other $80-85 \%$ of the young children may feel disenfranchised early in their life by being 
branded as "slow" by various degrees, especially, when they come from underprivileged families; unfortunately, they are the majority in the global population. We need to develop a system for knowledge creation, organization and delivery that is economically accessible, spiritually enlightening and applicable in the real world to a diversity of students. It must be available to all the people, all the time and all over the world. We need to develop updateable, high-quality, multimedia, and contextual education materials. We need to make the content easily available on the global web and it must be available at low cost. The contents must be customizable to the learning objectives and cognitive styles of the individual learners. We need intelligent software to aid customization.

\subsection{Effective teaching of diverse student population is a very complex process}

What are the exact cognitive processes and styles of different learners? What are the self-actualizing learning objectives of diverse people in a changing world that is continuously accelerating? What are the types of natural intelligences of people that may help us customize the style of presentation of the educational materials? These are all fuzzy and controversial, soft, social-science issues, yet they are critical in defining long-term educational philosophy.

We propose to make the whole world an experimental school through the use of the Global Internet. Thus, we must consciously facilitate diversity of experiments around the world that intend to meet the various local needs and we should organize ourselves to learn from each others successes, as well as failures, to accelerate our collective progress. We must develop collaborative understanding between all local optics education schools and institutions along with all the global photonics industry clusters. So, let us try to develop a flexible, but a concrete infrastructure that will allow numerous, unbiased experiments, results of which can be freely shared for rapid evolution of all of us.

\section{A concrete example: the Global Photonics Education Network (GPEN)}

Implementation of the philosophy and solutions proposed in the first part of this paper, require a concerted effort on the global scale. We present here an example of such an effort aimed at the photonics education sector: the Global Photonics Education Network (GPEN).

As part of the Education and Training in Optics and Photonics (ETOP) conference held in Singapore in November 2001, a panel discussion entitled "Global Networking to Promote Local Technician Education - Problems and Solutions" was held. Members from 9 countries exchanged view on the subject and agreed to form a global network to address local issues in photonics education and training. This led to the creation of the GPEN. In what follows, we review what has happened since, and present a plan of what could happen in the future for the GPEN. This draft plan is serving as a start for further discussion on the GPEN and is not intended to be final by any stretch of the imagination. Feedback from current and future "global networking enthusiasts" will shape this plan and enable it to become the blueprint for a more formal and firmly established the GPEN, with a clear direction and mandate [1]. This draft plan has been the object of discussions at the SPIE Annual Meeting in San Diego, CA (3-8 august 200) and at the ETOP 2005 conference in Tucson, AZ (6-8 October 2003). The interested parties who couldn't attend those meetings should send their comments and suggestions by email to Drs. Marc Nantel (mnantel@pro.on.ca.) and Chandra Roychoudhuri (Chandra@phys.uconn.edu) for further circulation among the active volunteers.

\subsection{ETOP 2001 and the first Panel}

At the 2001 ETOP conference, a Roundtable Panel was assembled and organized by Prof. Chandrasekhar Roychoudhuri from the University of Connecticut (USA) and Tuan-Kay Lim from the Nanyang Technological University (Singapore). The Panel generated a report that was published in the ETOP 2001 proceedings [2]. The Panel discussed the following questions, as stated in its abstract:

- "The global Internet system has ushered in the Knowledge Age. Since the core infrastructure of the Internet is based on Fiber optics and semiconductor laser based technologies, the field of optics/photonics now enjoys a privileged position. Thus, Scientific and Technological Education in Photonics (STEP) is critical to enhance and/or maintain economic competitiveness in IT industries."

- "Expanding and extending educational facilities is an expensive, difficult and slow process even in developed countries."

- "High School and early college level education in optics/photonics science \& technology is critical to the economic well being of the optics and communication industries around the world." 
- $\quad$ "...] identify the various geographical (local) issues and solutions (actual and potential) that can be emulated globally through various networking possibilities, aided by international optics/photonics societies. We can take lessons from the successful concept of global networking between local optical industry clusters to promote sustainable economic growth."

Participants included the audience and panel members Chandrasekhar Roychoudhuri (Chair, USA), Bob Breault (USA), Judy Donnelly (USA), Art Guenther (USA), Dan Hull (USA), Roger Lessard (Canada), Marc Nantel (Canada), John Marsh (UK), Pierre Chavel (France), Ari Friberg (Sweden), Valery V. Tuchin (Russia), Ajoy Ghatak (India), Tuan-Kay Lim (Singapore), and John D. Love (Australia).

The panel discussions generated the following recommended actions:

(i) Organize an Optics Global Networking website with SPIE \& ICO sponsorship, and with the guidance of this Roundtable members as an Ad-Hoc Committee.

(ii) Get as many societies and industry clusters involved in this global networking as possible.

(iii) Organize regional nodes of this Global Network under the sponsorship of local society chapters and industry clusters.

(iv) Carry out global survey of various needs with the help of clusters and societies. This could lead to the standardization of the core, invariant, scientific portion of the curriculum, while the industry clusters can customize the rapidly changing technology portion locally [2].

Since the first Panel, the first recommendation above has been implemented: a discussion forum was graciously provided by SPIE on their webpage (http://spie.org/app/forums/, and then "Technician Education") to facilitate exchanges between Global Photonics Education Networking enthusiasts. SPIE also provided the GPEN organizers with a document outlining what would need to do to further the development of the Network. It was agreed with SPIE and the organizers of the ETOP 2003 conference that there would be continuing discussions on the Network at the 2003 SPIE Annual Meeting (San Diego, CA, USA, 3-8 August 2003) and at ETOP 2003 (Tucson, AZ, USA, 6-8 October 2003), where special meetings were held on the subject. This draft plan intended to suggest a possible way to go for the Network, and is the document that was discussed at those two meetings.

\subsection{Importance of "clusters"}

One recurring theme from the first Roundtable Panel discussion and subsequent exchanges dealt with the crucial role "clusters" could take in the formation and operation of the GPEN. A cluster is a group of local companies, educational institutions and other stakeholders rallying around a particular sector of the economy or industry [3]. By pooling resources, a cluster can network, share best practices, influence local political economics, and lobby provincial, state or federal levels of government. One of the essential aspects of a cluster is that it be local, regrouping members from within, say, a 50-100-km radius. In photonics, the industry clustering efforts are being promoted internationally by Dr. Bob Breault from Breault Research Organization in Arizona (USA). There exists now photonics industry clusters throughout the world [4].

It seems clear that a well organized Global Network in photonics education would be most useful if it can facilitate the access to all the diversity of global best practices to the local educational leaders explicitly interested in strengthening the business base of the local photonics industry clusters. Because of the inherently local nature of industry clusters, the GPEN, by virtue of its vision of providing the global photonics education infrastructure, could be the facilitator to build "cluster of clusters", or a "super cluster", to borrow a term from our colleagues in astronomy. The establishment of a local cluster requires some critical mass of industry and academic institutions interested in photonics and the dedication of a few individuals to organized and maintain it. This means that the GPEN should inspire academics and industry engineers and scientists to participate in GPEN activities that promote their local interests through their local or international societies. By promoting excellence in local technical and advanced education, by providing easy access to sharing global best practices, GPEN will naturally facilitate the start and growth of local photonics industry clusters. GPEN can provide useful resources to new and existing local chapters of SPIE, OSA, IEEE, etc., which, in turn, nurture local industry clusters. However, more focused organizations designed specifically to promote local photonics education for the specific purpose of accelerating the growth of local photonics industry, would be an important approach for many countries. A few of the interesting examples include the National Association for Photonics Education and Training (NAPET) in Singapore, the Ontario Photonics Education and Training Association (OPETA) in Canada (ww.opeta.ca), Photonics Valley in Paris, etc. We should note that most of the original participants of the 2001 Roundtable meeting are local education leaders and 
are involved in organizing and promoting photonics education in many new ways to reach out beyond the needs of their immediate institutions.

\section{GPEN's organization, and its future growth}

The GPEN, right now, is little more than a few people around the world, loosely bound by the spirit of one meeting in 2001, and follow-up meetings in 2002 and 2003, two proceeding papers and a SPIE discussion forum. While this doesn't look like much, the key ingredient is already there: people who care about photonics education and who have a global view of it. Where does one go from there?

\subsection{First thing first: communication links}

The single most important tool to set up for GPEN is a line of communication between its members and would-be members. The current format of the discussion forum on the SPIE webpage is not sufficient on its own. To add some immediacy to the exchanges, we will implement a four-pronged approach to be implemented in parallel: (i) a webpage, (ii) a web based discussion forum (currently, SPIE is providing), (iii) a list-serv email address, and (iv) regular meetings.

The list-serve is a single email address to which a member from the list sends an email that will reach all the other members of the list. It is the simplest way to reach everybody at the same time. When meetings have to be set, policy has to be discussed, new resources have to be publicized, it is a very useful tool. There is usually a list-serv manager who screens new applicants for relevance (would likely be the Chair of the GPEN). A general etiquette has to be followed when using list-servs to avoid mass mailing intended to only one member, or to avoid spam. There are several commercial but free list-serv providers where all the exchanges are archived and can be accessed only by the members of the list. SPIE, OSA, ICO could also decide to provide this service if it is within their capabilities. The most glaring limitation usually encountered with this mode of communication is a limit on the size of the messages, which greatly reduces the possibility of sending attachments...

...Which is why the list-serv is best used in tandem with a content-based webpage. The webpage would not be use for discussions and on-going exchanges per se, but for posting important resources that are of interest to the GPEN community in general. A look at the OPETA webpage at www.opeta.ca can give an idea of what can be implemented: Mission and Vision statements, news, membership list and links, photonics education resources, forms... If updated regularly, the webpage can be a precious resource for members and non-members alike. This is where one could post a calendar of events (special meetings, conferences, workshops, and call for proposals), recently published photonics education standards, new curriculum and research papers, for example. Web hosting is relatively cheap, and it is best for the global community that it be administered by our international societies (SPIE, OSA, ICO, LIA, IEEE...) with the necessary coordination... The content of the webpage would be provided by members and international societies. A "paid members only" section could be implemented if some of the content has financial value like books, special proceedings, etc.

While distance communication is necessary for any endeavor on the global scale, face-to-face meetings are still the best way of exchanging and networking. Regular meetings could be arranged in cooperation with large international conferences worldwide such as the ETOP, SPIE, OSA, ICO, IEEE-LEOS, etc., and other similar events in Europe, Asia, Oceania and Africa. These could be divided in GPEN general meetings where issues of interest to the whole network would be discussed and decided upon, and GPEN local meetings looking after the more local needs. Minutes and reports of these meetings would be made available to the whole GPEN membership through the list-serv and the webpage. If the means are available, remote participants could join these meetings through teleconferencing, video-teleconferencing or web-teleconferencing, for example.

The current discussion forum on the SPIE webpage can still find a useful place in that format, especially since an increased communication between members through the list-serv will generate discussion threads that will be better expanded upon in the discussion forum (instead of crowding the list-serv with ongoing subject of interest to a specific but limited sub-group of the membership). Each prong of the four-pronged approach presented above should reinforce the others in a similar way, leading to more exchanges between global photonics education enthusiasts.

\subsection{The membership}

So far, the informal "members" of the GPEN have been the participants to the few past meetings. While it features a good international representation, the GPEN would no doubt have to recruit many more international participants to 
be truly representative of the global distribution of photonics education and training. Even though the first meeting, sponsored by ETOP-2001 Conference, focused on education for technicians, the formative spirit of GPEN has been broader - to promote education from grade school to life-long-learning (K-100!), including outreach and continuing education. The participants of the original meeting understood the significance and the importance of this broader vision. It is clear that there are a few groups from which GPEN should recruit:

- Photonics Education Clusters:

Those include organizations like OPETA in Ontario (Canada), NAPET in Singapore, Project PHOTON in New England (USA) and other groupings whose primary goals involve photonics education and training, at any and all levels. Mostly populated by educational institutions, outreach groups, government bodies and some industry members.

- Photonics Industry Clusters:

These are local industry associations with the advancement of the photonics industry at heart. They are usually composed of members from industry, government and academia. Examples include OPTIC and OPC in Ontario (Canada), AOIA in Arizona (USA) and the Optics Valley of China (PRC). Others in Europe were mentioned earlier.

- Professional societies:

There are members from SPIE, OSA, LIA, IEEE, APS and other organizations with a strong interest in photonics education and training. When the GPEN is better established, publicizing its existence to them would be beneficial for recruitment in general and for broadening the reach of the network.

- Conference participants:

The current "members" of the GPEN mostly involve people who attended ETOP 2001 in Singapore and the followup meetings in 2002 and 2003. As regular meetings co-located with major conferences take place, the chance to recruit more global networking enthusiasts will be increased.

\subsection{Vision and Mission, goals and deliverables}

Nothing has been formally laid down for the Vision, Mission, goals and deliverables for the Global Photonics Education Network. Partly, this is because it should be the membership who sets them. First, establish communications links, then populate them with interested parties, set up a loose governance and THEN proceed to lay down the organizational principles on which the GPEN will rest. The Vision and Mission statements, as well as goals and deliverables, are best set by the people who will populate the network, not the few who are keeping it greased and in working order. This still remains to be done by the GPEN membership at the time of this writing, but an example of what could emerge is shown below:

Vision: Facilitate the networking between local education promoters and all the available diversity of global best practices. (Just as the name "Global Photonics Education Network (GPEN)" literally implies.) While this vision statement can be improved and/or expanded by all the participating interested parties, the original international meeting at the ETOP-2001 was organized with this spirit of bringing the greater good to all photonics educators, students, and industry worldwide. This vision is also implicitly or explicitly embedded in the missions of almost all the Education Committees of the international societies. This brings the open question: "What should be the specific functional role and mission of GPEN?" Broadly speaking, it should function synergistically with the international professional societies and the photonics industry clusters to facilitate the formation of an effective network of education clusters. This is probably the key new function of GPEN that will synergize the functions of education committees of the international professional societies.

Mission: GPEN will achieve its Vision through following its five Mission statements:

(i) Facilitate the development of local photonics education clusters in support of GPEN and of local photonics educators;

(ii). Provide a networking opportunity for photonics educator with their colleagues from around the world;

(iii). Facilitate the free exchange and circulation globally of curriculum ideas, standards, aids and experiments;

(iv). Promote the spread of distance education in photonics (web-based or otherwise) to bring photonics education to all areas of the world, including to those below the critical mass to mount their own programs;

(v). Facilitate the formation of a united voice for the global photonics education community out of the locally diverse needs at different levels.

One can then drill down into the specifics of what the GPEN will want to accomplish and the priorities (both temporal and in importance) that it will set. This is especially true since for each goal/deliverable set there should be 
a dedicated sub-group of GPEN volunteers/members making it happen. Again, this is yet to be developed by the membership. Subjects that are likely to find themselves on the list of goals and deliverables include recruitment, internal and external communications, local cluster formation, photonics education and training needs analysis, and educational resources and programs. The list of possibilities is endless, and should reflect the priorities of the GPEN membership and of the individuals willing to push these agenda items to their fruition.

\subsection{Governance}

An organization like the GPEN would see little progress without some amount of structure in its governance, but too heavy a framework can collapse on itself, until its vision, mission and its services are well articulated. Once the specific nature of the organization is well defined, we will be in a position to emulate the right "Governing Structure" out of a wide variety of successful "non-profit" organizations and their "sub-organizations".

To accelerate the process of structural maturity, the Ad-Hoc Committee Members (the participants of the last several GPEN meetings) probably should elect an Ad-Hoc Chair and Ad-Hoc Vice-Chair for a definite period of time. During this period, the Chairs would be responsible to lead the development of a permanent organizational structure, based on the consensus recommendation extracted out of the Ad-Hoc Committee Members. The Ad-Hoc Chairs should also be empowered to form Ad-Hoc Sub-Committees to put GPEN in a functionally "running mode". Gathering this "running mode" experience is critical for our long-term success, as we are embarking on "nebulous", non-profit activities, which are already part of the desired functions of most of the professional societies. So, finding our functional niece, as a necessary and useful new organization (sub-organization), will be critical during the coming years.

\subsection{Budgetary considerations}

The costs to make a network like the GPEN happen can start at near zero if all that is wanted is a networking tool, and can climb limitlessly from then on as required by the goals/deliverable sets chosen. The bare minimum to starts the GPEN in a meaningful way is the list-serv (can be free), the webpage (free to the GPEN if provided by a member), the regular meetings at SPIE/OSA/ICO/IEEE-LEOS, etc., meetings (free to the GPEN provided by conference organizers and transportation/accommodation paid by the participants), the consumables (including longdistance telephone conversations, photocopying, faxing, mailing, can be expected as in-kind from members).

\section{Conclusion}

In this paper, we identify shortcomings of the current higher education paradigm and propose possible solutions.

One major problem is that higher education is currently reserved to the few who can afford it, while the vast majority of the population is missing out on fulfilling their intellectual potential. As part of the solution, in particular, we single out the recent globalization phenomenon and the way the internet and optical fibre telecommunications have enabled it. While the current education system has evolved from a time when the transmission of knowledge was difficult and costly (before paper, before printing), thereby limiting it to the well-off, we now live in an era when the World Wide Web makes available most of the knowledge ever generated virtually free of charge. This immense education potential must be tapped. We propose that global networking between educators can serve local education needs around the world through a more egalitarian distribution of knowledge and expertise. As an example, we present the Global Photonics Education Network, which aims to link optics/photonics educators worldwide to make education and training in that subject of a higher quality and more easily available to all parts of the world.

\section{Acknowledgements}

One of the authors (CR) would like to acknowledge partial support from the Phase-II of the NSF project, Scientific and Technological Education in Photonics (or, STEP-II). The other author (MN) would like to acknowledge the support of the Ontario Ministry of Entreprise, Opportunity and Innovation's Strategic Skills Investment Program, which is funding the "Photonics Education and Training for Critical Skills Shortages" project.

\section{References}

[1] M. Nantel, "Draft Plan for the Global Photonics Education Network - 29 July 2003”, unpublished. The draft plan for the Global Photonics Education Network is available through either authors at Chandra@phys.uconn.edu and mnantel@pro.on.ca.

[2] C. Roychoudhuri, "Global Networking to Promote Local Technician Education - Problems and Solutions", in Seventh International Conference on Education and Training in Optics and Photonics, T K Lim, ed., SPIE Proc. 4588A (2001). 
[3] M.E. Porter, “Clusters and the New Economics of Competition”, Harvard Business Review, Nov-Dec. 1998 (1998).

[4] See for example: the Arizona Optics Industry Association (www.aoia.org/AOIA/), the Florida Photonics Cluster (www.floridaphotonics.com), the Ontario Photonics Technology Industry Cluster (www.optic.on.ca), the Ottawa Photonics Cluster (www.ottawaphotonics.com), the Midland

Photonics Cluster (www.midlandsphotonicscluster.org), Optics Valley France (www.opticsvalley.org), Bayern Photonics e.V. (www.bayernphotonics.de), Australia Photonics CRC (www.photonics.crc.org.au), Optics Valley China (www.chinaov.org), and the cluster directory at www.photonicsclusters.org/cluster-list.dxp.

Proc. of SPIE Vol. $966396630 \mathrm{H}-8$ 